\title{
Relationship between Anthropometric indices, serum Leptin and Respiratory function in Myanmar male adult subjects
}

\author{
Thurein Zaw ${ }^{1}$, Zarchi Theint Theint Hlaing ${ }^{2}$, Mya Thanda Sein ${ }^{3}$ \\ ${ }^{1,2}$ Lecturer, ${ }^{3}$ Professor and Head, Department of Physiology, University of Medicine, Magway, Magway Regional \\ Division, The Republic of Union of Myanmar
}

Background: The role of leptin in respiratory function has been studied in specific respiratory disease. A little is known about the association of serum leptin level and respiratory function parameter in healthy subjects. Aims and Objectives: This study aimed to investigate the relationship between anthropometric indices, serumleptin and respiratory function in Myanmar male adult subjects. Material and Methods: A community- based cross-sectional comparative study was carried out in 101 apparently healthy male adult subjects of age 18-45 years. All participants were categorized by anthropometric indices into non- obese (body mass index: $\mathrm{BMI}<25 \mathrm{Kg} / \mathrm{m}^{2}$ andobese subjects $\left(\mathrm{BMI}>30 \mathrm{Kg} / \mathrm{m}^{2}\right)$. Differences in respiratory function parameter and serum leptin level were compared across the group. Spirobank // spirometer was used to measure respiratory function $\left(\mathrm{FEV}_{1}, \mathrm{FVC}, \mathrm{FEV}_{1} / \mathrm{FVC}, \mathrm{PEFR}\right.$ and $\left.\mathrm{FEF}_{25-75 \%}\right)$. Serum leptin level was investigated by enzyme-linked immunosorbent assay. Results: The percentage of predicted value of all respiratory function parameters of obese group was significantly lower than that of non-obese group $(p<0.05)$. All respiratory function parameters were significantly and negatively correlated with body mass index (BMI) and waist circumference (WC). Median and interquartile range of serum leptin level in obese group was 5.8(3.5-9.1) $\mathrm{ng} / \mathrm{mL}$ and it was significantly higher than that of non-obese group [1.9(1.1-3.1) $\mathrm{ng} / \mathrm{mL}$, $p<0.0011$. Serum leptin level was significantly and negatively correlated with respiratory function parameters (FVC, $\mathrm{FEV}_{1} / \mathrm{FVC}, \mathrm{PEF}$ and $\mathrm{FEF}_{25-75 \%}$ ). Conclusion: Respiratory function declined with increasing anthropometric indices might be due to increased serum leptin level considered as systemic inflammatory effect of body.

Key words: Respiratory function; Serum leptin; Obesity
Access this article online

Website:

http://nepjol.info/index.php/AJMS

DOI: 10.3126/ajms.v10i4.23974

E-ISSN: 2091-0576

P-ISSN: 2467-9100

\section{INTRODUCTION}

There are many evidences have been reported that obesity is associated with reduced respiratory function and it may be due to mechanical effect of obesity or inflammatory effect of obesity or both ${ }^{1}$. Many studies have been reported that serum leptin level is increased in obese subjects compared with non-obese control subjects. Serum leptin concentration is positively correlated with body mass index (BMI) and body fat percentage $e^{2,3}$. Adipose tissues secrete many proinflammatory mediators such as leptin, interleukin-6 (IL-6), interleukin -12 (IL-12) and tumor necrosis factor alpha $(\mathrm{TNF}-\alpha)^{4}$. Leptin is a $16 \mathrm{kD}$ a protein hormone and also known as "Ob gene" which is located on chromosome $e^{3}$. The main function of leptin is regulation of food intake and energy expenditure. Moreover, leptin is a proinflammatory mediator that promotes the release of other proinflammatory mediators and positively regulates the inflammatory process. Moreover, the presence of leptinreceptorsin human bronchial and alveolar epithelial cells, bronchial smooth muscle cells, and submucous bronchial membrane ${ }^{5}$ allow to assume that leptin takesa role in the regulation of airway diameter, lung development and the pathogenesis of respiratory diseases. The role of leptin in respiratory function has been studied in subjects with specific respiratory disease. However, there is a few 
studies about the association of serum leptin level and respiratory function parameter in healthy subjects.

Therefore, the present study measured and compared the respiratory function and serum leptin level in non-obese and obese Myanmar male adult subjects. Moreover, to explore the effect of leptin as a systemic inflammation on respiratory function in obesity, the present study investigated the relationship of anthropometric indices, respiratory function and serum leptin level in non-obese and obese male adult subjects.

\section{MATERIALS AND METHODS}

This was a community-based cross-sectional comparative study enrolled with hundred and one (30 non-obese, 71 obese) male adult subjects of age 18-45 years. All subjects gave written consent prior enrollment in this study. This study was approved by the Ethics and Research Committee of the University of Medicine, Magway.

\section{Inclusion criteria}

Apparently healthy subjects.

\section{Exclusion criteria}

Subjects with acute or chronic infections, being under any medication such as drugs affecting respiratory function and antioxidants, current smoker, current alcoholic and presence of known respiratory diseases, chest wall or spinal deformity and any intra-abdominal abnormalities.

\section{Anthropometric measurements}

Body weight,height and waist circumference (WC) were measured by using a weighing machine which is corrected zero error before the start of measurement and a measuring tape. Body mass index (BMI) was calculated by dividing the weight in kilograms by the square of the height in meters $\left(\mathrm{Kg} / \mathrm{m}^{2}\right)$. According to the WHO classification, a BMI of $18.5-24.9 \mathrm{Kg} / \mathrm{m}^{2}$ is non-obese and a BMI of $>30 \mathrm{Kg} / \mathrm{m}^{2}$ is obese. In obese subjects, WC $<90 \mathrm{~cm}$ were classified as generally obese subjects and $\geq 90 \mathrm{~cm}$ were classified as centrally obese subjects according to IDF, 2007.

\section{Respiratory function test}

Respiratory function parameters $\left(\mathrm{FEV}_{1}, \mathrm{FVC}, \mathrm{FEV}_{1} / \mathrm{FVC}\right.$, PEF and $\left.\mathrm{FEF}_{25-75^{\circ}}\right)$ were measured by using Spirobank II spirometer (910575, Medical International Research, Italy).

\section{Measurement of serum leptin level}

Blood samples were taken after overnight fasting and serum was separated by centrifugation method. Serum leptin levels were determined by Enzyme-Linked Immunosorbent Assay (Leptin immunoassay, DRG Instruments, Germany).

\section{Statistical analysis}

Data entry and analysis were done by SPSS software (Statistical package for Social Sciences) version 20 (IBM, Armonk, New York, United States of America). Respiratory function test values were described as mean \pm SD. Respiratory function test values were compared by using unpaired Student's “t” test. Serum leptin levels were expressed as medium and interquartile range and compared by using Mann-Whitney "U" test. Pearson's correlation was used to correlate between respiratory function and anthropometric data. Correlation between serum leptin level and respiratory function test values as well as anthropometric data were done by nonparametric (Spearman's rho) test. Significant level was set at $\mathrm{p} \leq 0.05$.

\section{RESULTS}

General characteristicsof the subjects in non-obese group and obese group are summarized in Table 1. Table 2 shows the percentage of predicted value of all respiratory function parameters of non-obese group and obese group. Median and interquartile range of serum leptin level were significantly different between non-obese group and obese group as shown in Figure 1. The correlation between serum leptinlevel and anthropometric measurements such as BMI

\begin{tabular}{|c|c|c|}
\hline Variable & Non-obese group $(n=30)$ & Obese Group(n=71) \\
\hline Weight $(\mathrm{Kg})$ & $60.33 \pm 4.15$ & $86.35 \pm 8.93$ \\
\hline Height $(m)$ & $1.62 \pm 0.51$ & $1.65 \pm 0.06$ \\
\hline $\mathrm{BMI}\left(\mathrm{Kg} / \mathrm{m}^{2}\right)$ & $22.99 \pm 1.08$ & $31.59 \pm 2.11$ \\
\hline WC $(\mathrm{cm})$ & $75.27 \pm 4.08$ & $96.08 \pm 3.35$ \\
\hline
\end{tabular}

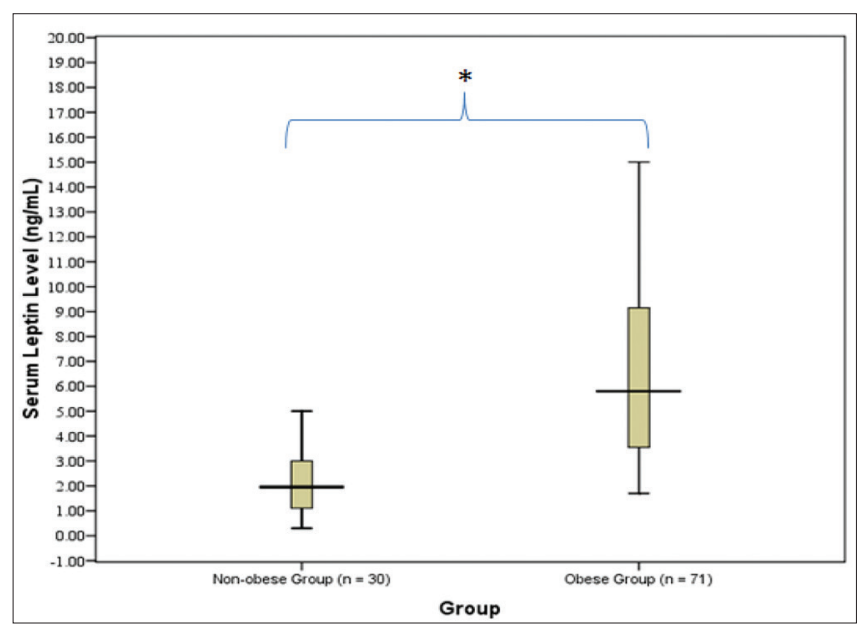

Figure 1: Comparison of serum leptin level in non-obese group $(n=30)$ and obese group $(n=71)$. Solid line represents medium value of serum leptin level. *indicates significant difference at $p<0.001$. Comparison was done by Mann-Whitney "U” test 


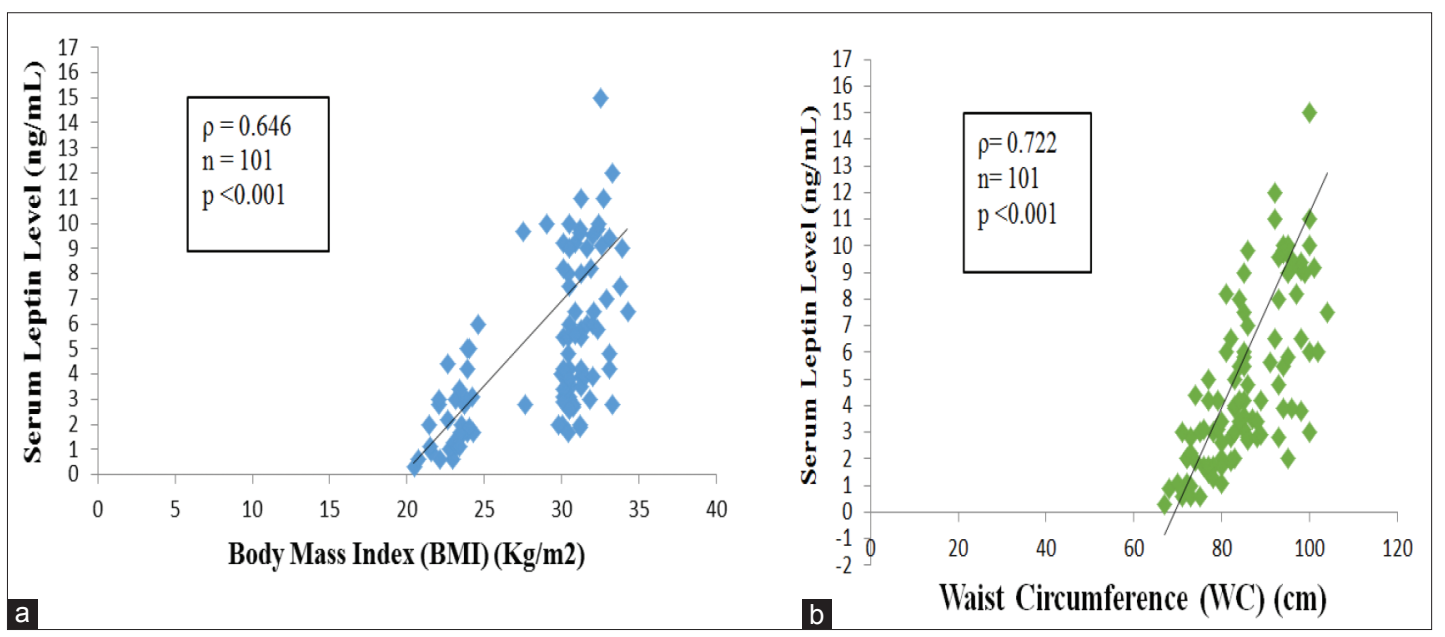

Figure 2: (a) Correlation between serum leptin level and BMI. (b) Correlation between serum leptin level and WC. $\rho$ : Spearman's rho correlation coefficient, $\mathrm{n}$ : Total number of subjects, Correlation was done by using non-parametric test (Spearman's rho test).

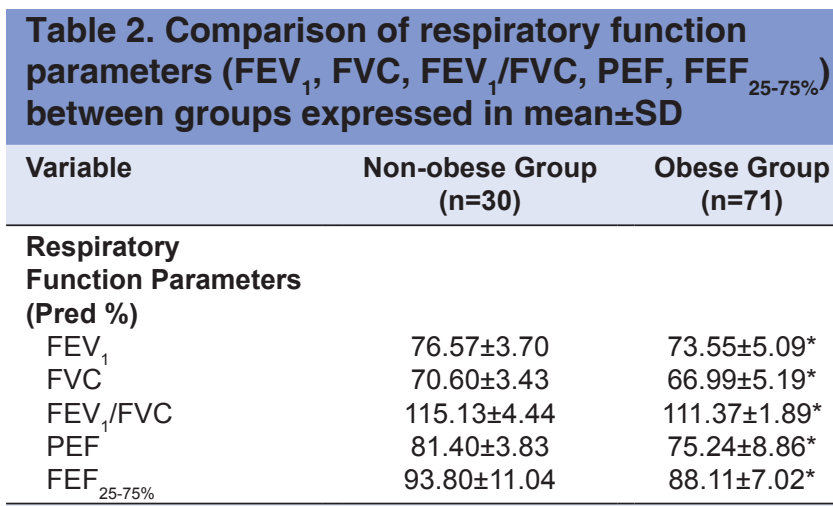

Statistical analysis was done by unpaired Student's " $t$ " test. $P<0.05$ was considered

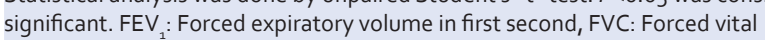
capacity, FEV /FVC: Ratio of forced expiratory volume in first second and forced vital capacity, PEF: Peak expiratory flow, FEF 2 $_{250 \%}$ : Average forced expiratory flow between $25 \%$ and $75 \%$ of FVC, Pred $\%$ : Percentage of predicted value SD: Standard deviation, * indicates significant difference at $\mathrm{P}<0.05$ between non-obese group and obese group.

and WC is shown in Figure $2 \mathrm{a}$ and $\mathrm{b}$. Table 3 shows the correlation between the percentage of predicted value of all respiratory function parameters and anthropometric parameters. The negative correlation between respiratory function parameters and serum leptin level was shown in Table 4.

\section{DISCUSSION}

A total of 101 adult male subjects (30 non-obese subjects and 71 obese subjects) participated in the present study. As the individual gets older, respiratory function declines. Gender difference has also effect on respiratory function because of difference in body fat distribution and hormonal factor ${ }^{6}$. Therefore, only young adult male subjects were recruited in the present study to avoid the influence of age and gender on respiratory function as well as serum leptin level.

Table 3. Correlation between BMI and WC with
percentage of predicted value of respiratory
function parameters
Parameters
Correlation with BMI

\begin{tabular}{|c|c|c|}
\hline Parameters & $\rho$ & $\mathbf{p}$ \\
\hline \multicolumn{3}{|c|}{ Correlation with serum leptin levels } \\
\hline $\mathrm{FEV}_{1}$ & -0.130 & 0.197 \\
\hline $\mathrm{FVC}$ & $-0.232^{*}$ & $<0.05$ \\
\hline $\mathrm{FEV}_{1} / \mathrm{FVC}$ & $-0.3^{*}$ & $<0.05$ \\
\hline PEF & $-0.401^{* *}$ & $<0.001$ \\
\hline $\mathrm{FEF}_{25-75 \%}$ & $-0.931^{*}$ & $<0.05$ \\
\hline
\end{tabular}

$\mathrm{FEV}_{1}$ : Forced expiratory volume in first second, FVC: Forced vital capacity, FEV $/ F V C$ : Ratio of forced expiratory volume in first second and forced vital capacity, PEF: Peak expiratory flow, $\mathrm{FEF}_{25-75 \%}$ : Average forced expiratory flow between $25 \%$ and $75 \%$ of FVC, $\boldsymbol{\rho}$ : Spearman's rho correlation coefficient

In the present study, respiratory function of the study population was measured by Spirobank II spirometer (910575, Medical International Research, Italy). Spirometry is an invaluable screening test of general respiratory health ${ }^{7}$. 
According to ATS/ERS guidelines, the same protocol was applied exactly to all subjects of this study to obtain accurate and precise measurement of $\mathrm{FVC}^{9}$. The observed values were converted to the percentage of the predicted values to avoid the confounding effects of age, height and ethnic group.

After analyzing the data, we found that there was a significant decreased in respiratory function parameters (FEV1, FVC, FEV1/FVC, PEF and FEF25-75\%) of obese subjects $(\mathrm{n}=71)$ compared to non-obese adult male subjects $(\mathrm{n}=30)(\mathrm{p}<0.05)$. However, the percentages of predicted values of respiratory function parameters of nonobese and obese subjects were normal according to Global Initiative for Chronic Obstructive Lung Disease (2017) classification. The results of the present study are same with previous study done by Sugerman et al., 1997, and Durgesh et al. 2013 8 . According to the study of Naimark and Cherinak, the increased adiposity around ribs, diaphragm and abdomen leads to limited movement of ribs, decreased total thoracic and pulmonary volume causing reduction in chest wall compliance and preventing full excursion of the diaphragm. It adversely affects chest wall mechanics and causes a decrease in total respiratory compliance ${ }^{10}$. It might be the cause of decreased respiratory function in obese subjects compared with non-obese subjects in the present study.

In the present study, there was a significant negative correlation between $\mathrm{BMI}$ and respiratory functions such as $\mathrm{FEV}_{1}, \mathrm{FVC}, \mathrm{FEV}_{1} / \mathrm{FVC}, \mathrm{PEF}$ and $\mathrm{FEF}_{25-75 \%}$. These findings agree the results of previous studies done by Saxena et al., (2009); Soundariya\&Neelambikai, (2013) and Shenoy\&Jagadamba, (2016) ${ }^{11,12,13}$. Waist circumference was also significantly and negatively correlated with respiratory functions such as $\mathrm{FEV}_{1}, \mathrm{FVC}, \mathrm{FEV}_{1} / \mathrm{FVC}$, PEF and $\mathrm{FEF}_{25-75 \%}$ in the present study. This finding of the present study was in line with studies of Saxena et al.,(2009); Soundariya\&Neelambikai (2013) and Shenoy\&Jagadamba (2016) which reported that there was negative correlation between WC and respiratory functions ${ }^{11,12,13}$. It was also noted that $1 \mathrm{~cm}$ increase in WC was associated with a $10 \mathrm{~mL}$ reduction in $\mathrm{FVC}$ and $4 \mathrm{~mL}$ reductionin FEV1 on observed value of the present study.

Since obesity is a chronic low-grade systemic inflammatory disease, another additional possible cause of respiratory function decline in obesity may be systemic inflammation ${ }^{14}$. Zaw et al., 2018 also reported that systemic low-grade inflammation due to obesity affect the respiratory function in obesity ${ }^{15}$. Subcutaneous adipose tissue and visceral adipose tissues secrete many inflammatory mediators such as leptin, TNF- $\alpha$ and IL- $6^{4}$. Leptin is a protein hormone and contains 167 amino acids. It is produced by the adipose tissue mainly by the white adipose tissue. It has an important role in inflammatory responses because leptin is a proinflammatory mediator.Loffreda et al., reported that leptin have an important role in upregulating the inflammatory system.

The present study also reportedthat serum leptin level was significantly higher in the obese group [5.8(3.5-9.1) ng/mL] than non-obese group [1.9(1.1-3.1) ng/mL, $\mathrm{p}<0.001]$. The present study also showed a significant positive correlation between serum leptinlevel and BMI $(\rho=0.519, \mathrm{n}=101$, $\mathrm{p}<0.001)$ as well as WC $(\rho=0.547, \mathrm{n}=101, \mathrm{p}<0.001)$. This result is similar to that observed by previous studies ${ }^{16,17,18}$.

In the present study, there was a significant negative correlation between percentage of predicted value of respiratory functions (FVC, $\mathrm{FEV}_{1} / \mathrm{FVC}, \mathrm{PEF}$ and $\left.\mathrm{FEF}_{25-75 \%}\right)$ and serum leptin level in study population (Table-4). according to the study done by Meire and Gressner (2004), leptin promotes the release of proinflammatory cytokines such as IL-6, IL-1 and TNF $\alpha$ from macrophages ${ }^{19}$. Schols et al., also reported that leptin is a potent inflammatory promoter and it may exacerbate existing systemic and lung inflammation which may cause reduced respiratory function ${ }^{20}$.

Among the respiratory function parameters, $\mathrm{FEF}_{25-75 \%}$ the predictor of small airway function was strongest correlation with serum leptin level (Spearman's rho correlation coefficient $\rho=0.93, p<0.05$ ). In animal studies, expression of leptinreceptor has been described in bronchial epithelial cells, alveolar macrophages and tracheal smooth muscle ${ }^{21,22}$. An in vitro study done by Bruno et al.(2009) investigated the presence of leptin and its receptor on human bronchial epithelial cellsof subjects with mild, uncontrolled, untreated asthma and reported that severe asthma was associated with a reduced expression of leptin and its receptor. Accordingly, the evidence of leptinreceptors expression in human lung tissue together with local leptin production supports the concept that leptin may play a role in the regulation ofairway diameter ${ }^{23}$. Obesity is commomly interpreted as evidence of leptin resistance since leptin regulate food intake and body weight. Thus, strongest negative correlation of $\mathrm{FEF}_{25-75 \%}$, the predictor of small airway function and systemic serum leptin level in present study indicated that leptin might contribute to regulation of airway diameter as leptin resistance state.

\section{CONCLUSION}

In the present study, there were significant decreases of all respiratory function parameters in obese group compared with non-obese group. Moreover, serum leptin level was 
significantly higher in the obese group than non-obese group. There was also a significant negative correlation between serum leptin level and respiratory function parameters especially $\mathrm{FEF}_{25-75 \%}$. Therefore, it can be concluded that obesity -induced hyperleptinemiamay result in leptin resistance and leading to small air way function decline.

\section{ACKNOWLEDGEMENTS}

We would like to thank all participants from Magway Township who willingly gave consent to this study and Professor Aye AyeOo, Professor and Head, Department of Preventive and Social Medicine, University of Medicine, Magway for sampling method and data analysis.

\section{REFERENCES}

1. Lessard A, Almeras N, Turcotte H, Tremblay A, Despres JP and Boulet LP. (2011). Adiposity and pulmonary function: Relationship with body fat distribution and systemic inflammation. Clinical and Investigative Medicine 2011; 34(2):64-69.

2. Verdich C, Toubro S, Buemann B, Holst JJ and Bulow J.Leptin levels are associated with fat oxidation and dietary-induced weight loss in obesity. Obes Res 2001; 9:452-461.

3. Farooqi IS, Matarese G, Lord GM, Keogh JM and Lawrence E. Beneficial effects of leptin on obesity. J Clin Invest 2002; 110:1093-1103.

4. Mohamed-Ali V, Pinkney JH and Coppack SW. Adipose tissue as an endocrine and paracrine organ.International Journal of Obesity Related Metabolic Disorders 1998; 22:1145-1158.

5. Neveu WA, Allard JL, Dienz O, Matthew JW, Gennaro C, Laurie AW and Mercedes R. IL-6 is required for airway mucous production induced by inhaled fungal allergens. The Journal of Immunology 2009; 10: 1731-1738.

6. Chen $\mathrm{HI}$ and Kuo CS. Relationship between respiratory muscle function and age, sex and other factors.Journal of Applied Physiology 1989; 66(2):943-948.

7. Miller MR, Crapo R, Hankinson J, Brusasco V, Burgos F, Casaburi R, et al. General considerations for lung function testing. European Respiratory Journal 2005; 26:153-161.

8. Sugerman $\mathrm{H}$, Windsor A, Bessos $\mathrm{M}$ and Wolfe L. Intra-abdominal pressure, sagittal abdominal diameter and obesity comorbidity. Journal of Internal Medicine 1997; 241:71-79.

9. Durgesh K, Neyaz HS, Rajeev P, Vinay A, Vibha G and Lata AM.
Spirometric evaluation of lung functions in obese and non-obese subjects. Journal of Advance Researches in Biological Sciences 2013; 5(3):229-233

10. Naimark A and Cherinak RM. Compliance of the respiratory system and its components health and obesity.Journal of Applied Physiology 1960; 15:377-382.

11. Saxena $Y$, Sidhwani $G$ and Upmanyu R. Abdominal obesity and pulmonary functions in young Indian adults: A prospective study. Indian Journal of Physiology and Pharmacology 2009;53(4):318-326.

12. Soundariya $\mathrm{K}$ and Neelambikai $\mathrm{N}$. Influence of anthropometric indices on pulmonary function tests in young individuals. World Journal of Medical Science 2013; 9(3):157-161.

13. Shenoy $U$ and Jagadamba. Influence of central obesity assessed by conicity index on lung age in young adults.Journal of Clinical and Diagnostic Research2016; 11(4):9-12.

14. Lessard A,Almeras N,Turcotte H, Tremblay A, Despres JP and Boulet LP. Adiposity and pulmonary function: Relationship with body fat distribution and systemic inflammation. Clinical and Investigative Medicine2011; 34(2):64-69.

15. Zaw T, Yee NN, SeinMT. Relationship between respiratory function and serum interleukin-6 (IL-6) level in non-obese and obese male adult subjects. International Journal of Clinical and Experimental Physiology2018; 5:99-104.

16. Sin DD and Man SSFP. Impaired lung function and serum leptin in men and women with normal body weight: a population based study. Thorax2003; 58:695-698.

17. Martin G, Myers Jr, Leibel RL, Seeley RJ and Schwartz MW. Obesity and Leptin Resistance: Distingushing Cause for Effect. TredsEndocrinolMetab 2010; 21(11):643-651.

18. Eising JB, Witerwaal SPM, Evelein AMV, Vissseren FLJ and van der Ent CK. Relationship between leptin and lung function in young healthy children. EurRespirJr 2014; 43:1189-1192.

19. Meire $U$ and Gressner AM. Endocrine regulation of energy metabolism: review of pathobiochemical and clinical chemical aspects of leptin, ghrelin, adiponectin, and resistin. ClinChem 2004; 50: 1511-1525.

20. Schols AM, Creutzberg EC and Buurman WA. Plasma leptin is related to proinflammatory status and dietary intake in patients with chronic obstructive pulmonary disease. Am J RespirCrit Care Med 1999; 160:1220-1226.

21. Bergen HT, Cherlet TC and Manuel P. Identification of leptin receptors in lung and isolated fetal type II cells. Am J Respir Cell MolBiol 2002; 27:71-77.

22. Nair $P$, Radford $K$ andFanat $A$. The effects ofleptin on airway smooth muscle responses. Am J Respir Cell MolBiol 2008; 39:475-481.

23. Bruno A, Pace E andChanez P.Leptin and leptin receptor expression in asthma.J Allergy ClinImmunol 2009; 124:230-237.

\footnotetext{
Authors Contribution:

TZ- Conceptualized and executed the study, literature search, collected data and statistically analyzed and interpreted, prepared first draft of manuscript: ZTTH- Concept and design of thestudy,reviewed the literature, statistical analysis and Interpretation of data, participated in drafting; MTS- Concept and design of the study, review of study, critical revision of the manuscriptfor intellectual content, approved the manuscript to be published.

Work attributed to:

Department of Physiology, University of Medicine, Magway, Magway Regional Division,The Republic of Union of Myanmar.

Orcid ID:

Dr. Thurein Zaw - (i) https://orcid.org/0000-0001-8565-5513

Dr. Zarchi Theint Theint Hlaing - (1) https://orcid.org/0000-0001-5452-5070

Prof. Mya Thanda Sein - (1) https://orcid.org/0000-0002-5135-3418

Source of Support: Nil, Conflict of Interest: None declared.
} 